\title{
Introduction
}

\section{Treatment of Chronic Scapholunate Ligament Injury}

Toshiyasu Nakamura, MD, $\mathrm{PhD}^{1}$

${ }^{1}$ Clinical Research Center, International University of Health and Welfare, Tokyo, Japan

J Wrist Surg 2015;4:229.

Chronic scapholunate (SL) ligament injury has been recognized as one of the most common disorders of the wrist, but also one of the most difficult injury to treat. Strategies for treatment of a chronic SL ligament injury can be grouped into those that involve: (1) correction of the flexed scaphoid; (2) reconstruction of the dorsal SL ligament (boneligament [retinaculum]-bone reconstruction); (3) reconstruction of the volar SL ligament; (4) reconstruction of both the dorsal and volar SL ligaments; and (5) interosseous ligament reconstruction. There is no gold standard of treatment, however, for all chronic SL ligament injury patterns.

This issue explores the various options, including some standard, time-tested techniques, as well as some novel approaches. Although we may still be wandering in the wilderness in some ways, we need to move ever forward in our quest for a cure for one of the last unsolved mysteries of the wrist.
Address for correspondence Toshiyasu Nakamura, MD, PhD, Department of Orthopaedic Surgery, Sanno Hospital, Clinical Research Center, International University of Health and Welfare, 8-10-16 Akasaka, Minato-ku, Tokyo, 107-0052, Japan (e-mail: toshiyasu@ae.em-net.ne.jp).
Copyright $\odot 2015$ by Thieme Medical Publishers, Inc., 333 Seventh Avenue, New York, NY 10001, USA. Tel: +1(212) 584-4662.
DOI http://dx.doi.org/ $10.1055 / \mathrm{s}-0035-1565924$. ISSN 2163-3916. 